\title{
MOVIDAS PELO AFETO:TRÊS MULHERES NA RESISTÊNCIA À DITADURA NO BRASIL, PARAGUAI E BOLÍVIA (1954-1989)
}

\author{
Cristina Scheibe Wolff ${ }^{1}$ \\ Tamy Amorim da Silva ${ }^{2}$
}

\section{Resumo:}

Neste artigo são discutidas as relações de afeto e o comprometimento político nos movimentos que lutaram pelos Direitos Humanos durante as ditaduras civil-militares no Brasil, na Bolívia e no Paraguai, focando o olhar em três mulheres que ocuparam um lugar de reconhecimento na resistência à ditadura. São elas: Therezinha Godoy Zerbini, líder do Movimento Feminino pela Anistia, no Brasil; Carmen Casco Miranda de Lara Castro fundadora da Comissão de Defesa dos Direitos Humanos do Paraguai e, Loyola Guzmán Lara, organizadora da Associação de Detidos, Desaparecidos e Mártires de presas/os e desaparecidas/os na Bolívia. Portanto, o objetivo deste trabalho é propor uma análise comparativa entre a ação política dessas três mulheres, em três países diversos, para entender como agiam em um momento em que a ditadura paralisava muitas pessoas.

Palavras-chave: Gênero. Direitos Humanos. Ditaduras Militares.

\section{Introdução}

O afeto é um estado da alma e, de acordo com Spinoza, pode aumentar nossa vontade de agir. Certamente o afeto foi um importante componente na busca por justiça de muitas mulheres e homens que, durante as ditaduras do Cone Sul, colocaram suas vidas em risco para denunciar as violações aos Direitos Humanos, as torturas e desaparecimentos de seus filhos e filhas, companheiros e amigos. $O$ presente artigo visa apresentar três mulheres que se tornaram defensoras dos Direitos Humanos em seus países no Cone Sul, mais precisamente no Paraguai,

\footnotetext{
${ }^{1}$ Doutora em História Social pela Universidade de São Paulo, São Paulo, SP. Professora Associada do Departamento de História da Universidade Federal de Santa Catarina, Florianópolis, SC. Atua no Programa de Pós-Graduação em História e no Programa de Pós-Graduação Interdisciplinar em Ciências Humanas da Universidade Federal de Santa Catarina, Florianópolis, SC. Bolsista de Produtividade em Pesquisa do CNPq. É uma das coordenadoras editoriais da Revista Estudos Feministas. E-mail: cristina.wolff@ufsc.br

${ }^{2}$ Graduada em História, Licenciatura e Bacharelado pela Universidade Federal de Santa Catarina, Florianópolis, SC. Apoio Técnico-CNPq do Laboratório de Estudos de Gênero e História. E-mail: tamyamorim@gmail.com
} 
Bolívia e Brasil', e discutir os cruzamentos dessa história. Carmem Lara Castro, Loyola Guzmán e Therezinha Godoy Zerbini foram fundadoras e organizadoras das organizações de familiares desaparecidos e detidos e movimentos pela anistia entre as décadas de 1960-1980, durante o período que se conhece no Cone Sul pelos governos de cunho autoritário e repressivo. ${ }^{4}$ Cada uma delas teve seus próprios motivos para engajar-se nessa luta menosprezando a repressão, condicionantes de gênero e o medo. Essas três mulheres mostraram protagonismo político então reservado a figuras masculinas nesses países, liderando movimentos que tiveram papel significativo na redemocratização dessas sociedades, posteriormente.

As organizações de familiares de presos e desaparecidos e movimentos pela anistia surgiram relacionados às violações de Direitos Humanos cometidos pelos regimes autoritários. O perfil dos integrantes desses movimentos era bastante variado, apesar de terem uma postura apolítica, entre outros motivos, para neutralizar a repressão, havia no interior dessas organizações a participação de exguerrilheiros, intelectuais de esquerda e estudantes. Embora a literatura sobre 0 assunto $^{5}$ destaque que o compromisso dessas mulheres com os movimentos raramente vinha de convicções ideológicas democráticas ou de cálculos estratégicos, sugerindo que as mulheres foram movidas pelo afeto diante da repressão a lutar por seus familiares, e amigos, que haviam caído nas mãos do Estado, o caso dessas três mulheres é um pouco diferente. Como se verá na trajetória de cada uma delas, de distintas formas elas estavam desde o início comprometidas com ideais e organizações políticas, nas quais, talvez por serem mulheres, não eram consideradas lideranças, o que não impedia sua adesão. Gradualmente, com a experiência de luta tornaram-se figuras públicas que reivindicavam pelo retorno à democracia (JELIN, 2006, p. 263).

O objetivo deste artigo é comparar a ação política dessas três mulheres para entendermos como surgiram essas associações, e quais foram os motivos para se organizarem em torno de grupos de assistência aos familiares de presos e desaparecidos políticos. Em cada trajetória buscamos outro olhar sobre a história

\footnotetext{
${ }^{3}$ As ditaduras se iniciaram nestes países respectivamente: Paraguai em 1954, Brasil em 1964, Bolívia em 1964 (SADER, JIKINGS, 2006, p. 900, 222, 192).

${ }^{4} \mathrm{O}$ tipo característico de regime ditatorial das últimas décadas do século XX foi o governo militar baseado na doutrina de segurança nacional, que se concentrou no Cone Sul do Continente. Ver em: (SADER, JIKINGS, 2006, p. 412).

${ }^{5}$ Elizabeth Jelin, por exemplo, trabalha com este enfoque de que as mulheres primeiramente foram movidas pelo afeto e que raramente seriam levadas a participar de algum movimento por razões ideológicas. Ver em: (JELIN, 2006, p. 263).
} 
dos movimentos de resistência à ditadura, ou seja, através dessas histórias individuais, visamos ampliar nosso entendimento sobre esse importante momento em que as mulheres passaram a fazer parte do cenário político (JELIN, 2006, p. 264).

Para analisar a trajetória de Therezinha Zerbini, utilizamos o livro "Anistia Semente da Liberdade" que reúne uma série de entrevistas feitas - no período de 1975-1979 que é o tempo de duração do movimento pela Anistia - aos jornais, além de utilizar artigos e a Tese da Ana Rita Fonteles Duarte (2009) que fez um grande estudo sobre o Movimento Feminino pela Anistia, trazendo grande número de entrevistas com ex-integrantes do movimento no Ceará, e da própria líder do movimento Therezinha G. Zerbini. Sobre Carmem Lara Castro, falecida na década de 1990, utilizamos a entrevista feita com seu filho, Jorge Lara Castro, que participou da Comissão de Direitos Humanos do Paraguai. Apenas Loyola Guzmán foi entrevistada no âmbito do grupo de pesquisa do Laboratório de Estudos de Gênero e História.

Sobre a participação das mulheres nas organizações de Direitos Humanos e na cena política e pública no Cone Sul, podemos ressaltar o trabalho de Elizabeth Jelin. Ela aponta para a importância das mulheres em duas formas de ação "tipicamente femininas":

Dos tipos de acciones "típicamente femeninas" se dieron en ese contexto: en la escena pública, la creación de organizaciones de derechos humanos ancladas en el parentesco con las víctimas directas; en el ámbito privado, la lucha por la subsistencia familiar y la adaptación o cambio en función de las nuevas circunstancias (2002, p. 104)

Também foi muito importante o trabalho de Alfredo Boccia Paz sobre a "Repressão política e de gênero na ditadura paraguaia" (2010. p. 74-93), que trouxe outra perspectiva ao tratar das artimanhas políticas do Estado de exceção no que concerne a repressão de gênero e como as mulheres se incorporaram ao espaço público e político no Paraguai durante o regime personalista do General Alfredo Stroessner.

Utilizamos a categoria gênero para esta análise como construção cultural da diferença sexual, que diferencia e distribui desigualmente atribuições entre homens e mulheres (SCOTT, 2005). Mas também como um dos elementos que configuram a 
emergência e o significado dos agentes políticos, no caso, das mulheres como porta-vozes da anistia e da reivindicação pelo respeito aos direitos humanos.

Brasil, Paraguai e Bolívia têm em comum na sua história recente a exclusão da população nos processos políticos de forma muito intensa (WOLFF, 2010, p 139). Então, o período escolhido para ser trabalhado está compreendido entre 1954-1989 por se tratar do início e do "fim" das ditaduras nestes países, e também o momento em que surgiu um intenso movimento pelos Direitos Humanos, assim como movimentos populares pela redemocratização.

As trajetórias de vida são histórias ${ }^{6}$ individuais que nos permitem voltar ao passado através da memória do narrador, neste caso, os entrevistados que ao fazer o relato oral se reconstituem no presente, reordenando sua trajetória e dando sentido a sua história e construindo sua identidade. Neste trabalho não focamos as histórias de vida de cada participante do movimento, mas buscamos nas suas trajetórias as condições para o surgimento desses movimentos e assim poder compará-los.

Para este trabalho, utilizamos a metodologia da História Oral procurando ampliar as possibilidades de interpretação sobre esse passado, possibilitando o acesso a "histórias dentro da história" (ALBERTI, 2008, p 115), por meio dos relatos orais. Através dos relatos de Loyola Guzmán e Jorge Lara Castro, filho de Carmem C. M. de Lara Castro, podemos compreender as motivações que levaram nossas protagonistas a fundar as associações. São olhares específicos sobre sua própria história ou a história de sua mãe, e suas versões do passado. Usamos a categoria gênero também para entender como papéis tradicionais como o de "mãe"7 foram invocados pelas mulheres durante a repressão, passando de função normativa e condição inerente à mulher à estratégias de lutas. As mulheres que se inseriram nessas organizações possuíam "armas" para lutar contra a ditadura, colocando-se ao lado da resistência política, elas acentuavam de maneira estratégica os

\footnotetext{
${ }^{6}$ História de vida "é o relato de um narrador sobre sua existência através do tempo, com a intermediação de um pesquisador. É um trabalho coletivo de um narrador-sujeito e de um intérprete" (PEREIRA, 2000, p. 118).

${ }^{7}$ As Madres argentinas são referência quando se fala do uso da maternidade para fins políticos, algo que ainda hoje é usado na busca pelos desparecidos, assim como em outras questões referentes aos Direitos Humanos. Ver em: TRINDADE, 2009, p. 40.
} 
estereótipos e suas próprias realidades, como meio de legitimação de sua causa: a proteção da família ${ }^{8}$, assim como uma forma de proteção.

Esse papel simbólico era perpetuado no imaginário social como "santificado", personagens particularmente dóceis, sensíveis e frágeis. Contudo, esse papel era relativamente dúbio, pois as mães podiam ser vistas como frágeis, mas também como leoas que defendiam suas crias, arriscando suas próprias vidas em troca da vida de seus filhos. Então, essas personagens atravessavam por esses caminhos, entre a "doçura e fragilidade" e a "bravura e coragem" de serem mães. ${ }^{9}$

Essas atribuições foram usadas em ocasião de extrema peculiaridade, estes países viviam em estado de guerra contra o "inimigo interno", o "comunismo", levado a situação limite de desaparecimento forçado de pessoas e pena de morte sem julgamento, isto devido a uma ideologia de Estado de Segurança Nacional. Nesse momento as "ameaças" vinham de todos os lados e a censura e a repressão tornavam-se palavras de ordem. Essas mulheres viviam sob o signo de ameaça, eram assim consideradas pelo aparato repressivo, o que tornava suas ações de desmascarar o sistema repressivo um risco.

Para poder cruzar esses olhares entre diferentes países e movimentos, utilizamos o Método Comparativo. ${ }^{10}$ Este trabalho não visa fazer uma comparação entre os países, mas entre os movimentos que neles surgiram e, assim, encontrar as semelhanças e diferenças entre as organizações. Isso fica mais claro quando se pensa que para além da história comparativa ${ }^{11}$, também estamos fazendo o que tem sido chamado por alguns de história "cruzada", histoire croisée, ou entangled histories. Ou seja, não estamos pensando que os países do Cone Sul são entidades separadas, que podem ser analisadas como contextos diferenciados, e comparadas, mas que a história que se viveu em cada um dos lugares onde nossas depoentes

\footnotetext{
${ }^{8}$ Geralmente esses movimentos se iniciaram com o objetivo de obter informações de familiares desaparecidos e levar melhores condições aos presos, mas durante a luta ampliavam seus objetivos. Sobre o uso estratégico do gênero nesses movimentos ver: CAPDEVILA, 2001. p.103-128.

${ }_{9}$ Uma demonstração desta ambiguidade é o movimento das Madres de Praza de Mayo, essas mães quando saíram às ruas fazendo suas vigílias e manifestações foram chamadas de "las locas" pelo Estado que se negava em responder as questões lançadas pelas mães em virtude de seus filhos desaparecidos. Como o Estado poderia fazer mal a mulheres que somente contavam com suas dores e angústias diante daquela situação. Ver em: DUARTE, 2009. p.32-35.

10 "método de pesquisa que convida a uma mudança de atitude no modo de fazer História; é uma nova perspectiva dos pesquisadores como sujeitos em relação ao objeto de pesquisa" (THEML; BUSTAMENTE, 2007, p. 16).

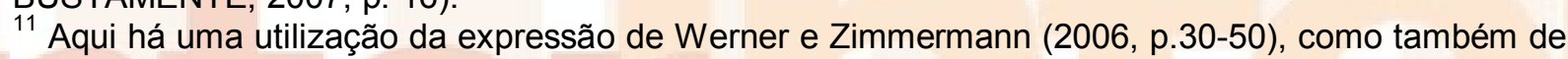
Kocka (2003, p. 39-44).
} 
estavam nas suas trajetórias estavam trançadas com as histórias de outros lugares e tempos.

Muitas mulheres que nesse momento levantaram a bandeira pelos Direitos Humanos lutaram por algo que Ihes parecia próprio de sua condição como mães, esposas e mulheres: "a defesa da família", não estavam "inovando" em sua luta, pois reivindicavam algo que acreditavam ser "pertinente à mulher", estavam levando o privado ao público. Mesmo assim, estavam adentrando um espaço que se acreditava ser inédito para as mulheres por ser masculino, o espaço público-político. Então, elas usavam estratégias para se esquivar da repressão e para conseguir informações de seus familiares, utilizando papéis de gênero, isto é, um estereótipo ou um papel tradicional como o de "mãe, defensora do lar, mulher", tão presentes ao imaginário social.

Após a virada linguística e a virada cultural, parece estar se delineando nas ciências sociais uma "virada emocional" (emotional turn). Com inspiração nas teorias que apontam para a importância da subjetividade e com um diálogo com a psicanálise, alguns autores têm apontado para novas possibilidades de interpretação histórica que levem em consideração os sentimentos e emoções.

Ao escrever uma história de "A invenção dos direitos humanos", Lynn Hunt (2009) inicia mostrando como a literatura, e especialmente os romances, no século XVIII foram capazes de criar em seus leitores uma "empatia" com os personagens, através da expressão de sentimentos, e foram bastante responsáveis pela criação da noção de direitos humanos, que implicava necessariamente em uma empatia entre todos aqueles que se considerava "humanos". Assim, esse tipo de emoção parece estar na base da própria noção de direitos humanos, que foi apropriada de forma muito contundente pelos movimentos de resistência às ditaduras.

Mas o que nos interessa realmente não é simplesmente as emoções. Não se trata de descrever que tipo de sentimentos eram experimentados, ou como isso aparecia nos materiais que estamos pesquisando. Estamos pensando nas emoções como constitutivas de discursos. Discursos que, por sua vez, foram práticas políticas de confrontação com os regimes militares, e que tiveram efetividade política na medida em que criaram empatias e auxiliaram na redemocratização da região.

Se num primeiro momento se pode dizer que a repressão política exercida pelas ditaduras foi efetiva no sentido de desmantelar as organizações de esquerda que atuavam nos países do Cone Sul, alguns com perspectivas revolucionárias; por 
outro lado, no campo da memória, foi a resistência a vencedora. Hoje, com os projetos "Nunca Más" (JOFFILY, 2011, p. 213-232), os numerosos julgamentos ocorridos na Argentina, e a atual Comissão da Verdade, no Brasil, parece estar se estabelecendo uma memória muito mais da violência exercida por essas ditaduras do que o que se sabia na época. Esse processo, porém, não se dá sem controvérsias, recuos e reinterpretações.

\section{Os caminhos da luta pelos direitos humanos no Cone Sul}

Por todo Cone Sul, onde as ditaduras militares se tornaram presentes entre as décadas de 1960-1970, surgiram associações pelos Direitos Humanos. Devido ao grande número de desaparecidos, exilados e detidos, na sua maioria, as organizações possuíam maior participação das mulheres do que de homens. Segundo o discurso corrente, a grande parcela atingida pela repressão eram homens, então as mulheres "tinham" de tomar a frente nesses movimentos ${ }^{12}$. Entretanto, essas organizações eram formadas por homens e mulheres, com a exceção do Movimento Feminino pela Anistia (MFPA), no Brasil, que tinha como estratégia a participação exclusiva de mulheres, diferentemente do Movimento das Madres argentinas, que teve sua incorporação feminina de modo espontâneo (DUARTE, 2009, p. 51). O MFPA iniciou seu trabalho em 1975 - ano instituído pela ONU como o Ano Internacional da Mulher -, com objetivo principal de lutar contra os atos de exceção e em prol da redemocratização do país (ZERBINI, 1979. p. 89). O Brasil vivia naquele momento o início do fim do regime militar, com sua lenta e gradual marcha para a transição democrática.

No Paraguai, o regime personalista do General Alfredo Stroessner, iniciado no ano 1954, era sustentado por seu partido político - Colorado -, e pelas Forças Armadas e uma polícia política. A Comisión de Defensa de los Derechos Humanos do Paraguay, criada no ano 1967, tinha em seu interior homens e mulheres que reclamavam pelos Direitos Humanos, esta comissão não apenas lutava pelos presos políticos e exilados, mas dava amparo aos necessitados (CASTRO, 2008, p. 3). Assim como o Movimento Feminino pela Anistia no Brasil, a Comissão de Defesa dos Direitos Humanos do Paraguai tinha fortes vínculos com a igreja, que também

\footnotetext{
${ }^{12}$ Podemos encontrar esses relatos em entrevistas feitas com Elena Fonseca, Moriana Hernandez, Loyola Guzmán. Todas as entrevistas se encontram no acervo de entrevistas do LEGH.
} 
atuou de várias maneiras em defesa dos Direitos Humanos. A ditadura personalista de Stroessner deixou um saldo de 20.090 vítimas de crimes aos Direitos Humanos, e segundo a Comisión de Verdad y Justicia atingiu indiretamente 107.987 pessoas, e 99.312 familiares ou pessoas que foram atingidos diretamente pela ditadura. (COMISIÓN DE VERDAD Y JUSTICIA, 2008, p. 46).

A Bolívia diferentemente desses dois países - que passaram por um regime militar mais longo - passou por sucessivos golpes e regimes ditatoriais e por parcos momentos de democracia. O período de golpes se iniciou em 1964, encabeçado pelo General René Barrientos, a partir dessa data os militares assumiram o poder na Bolívia e, igualmente aos outros países do Cone Sul, usaram as Forças Armadas como alicerce de seu poder, baseado no medo e na violência. O movimento de familiares que se iniciou na Bolívia, na década de 1970, continua ainda hoje sua busca, tornando-se indispensável para os familiares de mais 154 pessoas desaparecidas (ASSOCIACIÓN DE FAMILARES DE DETENIDOS DESAPARECIDOS Y MÁRTIRES POR LA LIBERATACIÓN NACIONAL, 2008, p. 19).

Contudo, nesses países surgiram outros movimentos sociais ${ }^{13}$ que possuíam em sua grande parte mulheres que lutaram por uma realidade melhor e mais justa. A causa delas também foi pelos Direitos Humanos, devido à realidade vivida em seus países ligados à extrema pobreza em função da inexistente distribuição de renda que gerava/gera milhões de famintos a cada ano. Paralelamente a essas organizações, surgiu outra modalidade de movimento social, o feminismo de segunda onda ${ }^{14}$, que lançava as questões sobre a opressão feminina e lutava pelo direito ao corpo, prazer, e contra o patriarcado. Grande parte desse movimento nasceu no exílio com as mulheres que foram estudar fora do país, ou que participaram de movimentos de esquerda, ou que acompanhavam seus companheiros e que partiram para o exílio - como forma de proteção contra a repressão -, na Europa e/ou na América do Norte entraram em contato com os círculos feministas, e ao retornaram para seus países trouxeram novas ideias de como pensar a condição da mulher na América Latina.

${ }^{13}$ Sobre os movimentos ver: No Brasil ver em: PINTO, 2003, p. 42-43. No Paraguai ver em: CORVALÁN, 1986, p.91-136. Na Bolívia ver em: VIEZZER, 1984, p. 305.

14 "Movimento surgido nos Estados Unidos e na Europa Ocidental, desde a segunda metade dos anos sessenta, nos países do Cone Sul a movimentação ocorreu a partir dos anos setenta" (PEDRO, 2010, p.115). 


\section{Na dialética da ditadura: somos mais mulheres?}

Partindo para as entrevistas observamos que os movimentos tinham em sua maioria a participação de mulheres e isso é explicado de duas formas por suas integrantes. No caso da associação surgida na Bolívia, Loyola Guzmán Lara salienta que havia mais mulheres, pois, mais homens estavam presos, por isso tinham de lutar (2008, p. 12). No outro caso, o Movimento Feminino pela Anistia permitia somente a presença de mulheres; neste movimento a exclusão de homens era tida como "estratégia de guerra", Zerbini - líder da organização - aponta que a presença de homens inibia a autonomia das mulheres, e a exclusão deles dava ao movimento características de "ausência de objetivos políticos" e "neutralidade", como bem salienta Duarte (2011, p. 250). Ou seja, na ação das mulheres do Movimento Feminino pela Anistia, temos a consciência de que se jogavam as estratégias de gênero para se manterem "seguras" da repressão, com uma aparência menos política, por se tratar de um movimento de mulheres. Mas, no caso do movimento de familiares da Bolívia, Loyola afirma que não era estratégia, mas necessidade de agir em prol de seus parentes (2008, p.10).

O uso de papéis tradicionais de gênero, como o de "mãe, protetora da família" ou pacificadora, teve como objetivo, consciente ou inconscientemente, inibir a repressão do Estado, pois era como se as mulheres estivessem interpretando papéis que "sempre" couberam a elas, como o de zelar pela família. Então, ao saírem às ruas pedindo informações de seus familiares, estavam agindo como "sempre" agiram. As ações dessas mulheres acabaram por denunciar os atos de crueldade cometidos em seus países, tanto no âmbito nacional como internacional, arrancando a máscara dos governos ditatoriais, baseados numa falsa moralização, milagres econômicos e pacificação.

Esse uso do gênero tem sido problematizado em vários trabalhos sobre o período das ditaduras (WOLFF, 2007 e DUARTE, 2009, p. ex.). Luc Capdevila (2001) em estudo comparativo entre Argentina e Bolívia, por um lado, e o contexto da Alemanha Nazista, de outro, também mostrava esse potencial do gênero como uma possibilidade de "jogar" com papéis normativos e uma agência que acaba por ser subversiva em determinados contextos. 


\section{Trajetórias cruzadas}

As trajetórias de Carmen C. M. de Lara Castro, Loyola Guzmán Lara e Therezinha G. Zerbini, por mais diferentes e complexas que sejam, se cruzam quando se trata da defesa dos Direitos Humanos, e isto ocorreu em momentos e lugares diferentes. Essas mulheres possuíam posições políticas dessemelhantes, mas a luta pela justiça prevaleceu em suas trajetórias.

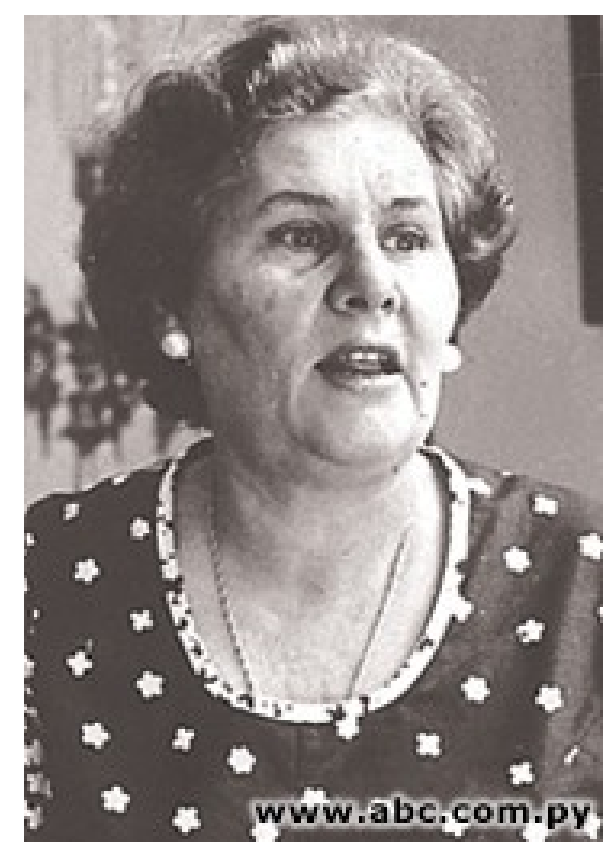

Fonte: (DIA DE LA MUJER PARAGUAYA, 2003)

Carmen Casco Miranda de Lara Castro nasceu em 1919, na cidade de Concepción, Paraguai, em uma família tradicional e filiada ao Partido Liberal. Seu pai Fermín Casco Espín foi general e lutou na guerra do Chaco, e seu tio José Félix Estigarribia presidente do Paraguai. Castro foi professora de Francês e Educação Cívica nos colégios de Assunção. Casou-se com Mariano Luis Lara Castro e teve seis filhos. Em 1940, o General Higínio Moríngio tomou a presidência do Paraguai (1940-1948), e iniciou um período de repressão. Nesses anos, Castro iniciou a luta pelos presos políticos por meio do Partido Liberal - Partido tradicional e moderado no Paraguai - do qual era filiada. Além disso, era comprometida também com a melhoria da Educação das mulheres, ajudou a fundar a Instituição Cultural Amparo 
Mujer, e foi editora da Revista Kuñatai ${ }^{15}$, essa revista fazia, entre outras coisas, protestos pelos desaparecimentos e sobre a participação da mulher na política. Castro continuou lutando por pessoas detidas e desaparecidas de forma informal teve diversas vezes seus filhos presos, até que organizou a Comissão de Direitos Humanos do Paraguai (1967). E, enquanto foi presidente desse grupo (1967-1993), entrou para o Partido Liberal Radical Autêntico - cisão do Partido Liberal, de 1978 -, pelo qual foi Deputada Constituinte entre os anos de 1977 e 1987 e senadora entre 1987 e 1993. Carmem Lara Castro faleceu em maio de 1993, em função de complicações com diabetes.

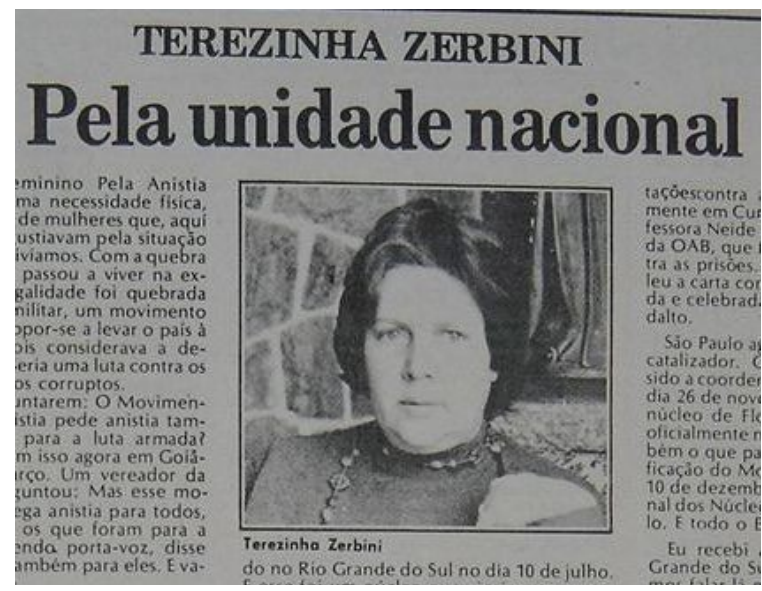

Fonte: (A PREGAÇÃO DAS MULHERES,

1978, $p, 13)$

Therezinha Godoy Zerbini nasceu em 1928 em São Paulo. Pertencente à classe média alta, foi esposa do General Euryale Jesus Zerbini, preso e cassado quando se deu o golpe civil-militar no Brasil em 1964. Foi, nesse processo de cárcere de seu esposo, que Zerbini iniciou a luta contra o regime. Contudo, sua ação aberta de oposição às violências cometidas pelo Estado, ocorreu praticamente dez anos após o golpe civil militar. Em 1975, Therezinha G. Zerbini organizou o Movimento Feminino Pela Anistia (MFPA), em São Paulo, e tratou de organizar outros núcleos pelo país por sete estados brasileiros (BA, MG, CE, PB, RS, SE e PE). A partir desse feito, Therezinha Zerbini tornou-se uma das principais vozes do grupo pela anistia, fazia palestras e dava entrevistas por todo Brasil. Durante a presidência do MFPA, Zerbini pontuava que a luta do movimento era pela

${ }^{15}$ A palavra Kuñatai em Guarani significa senhorita, moça.

R. Inter. Interdisc. INTERthesis, Florianópolis, v.10, n.1, p. 190-211, Jan./Jul. 2013 
pacificação do Brasil e pretendia, por meio da ação do grupo, conscientizar as pessoas sobre a causa da anistia.

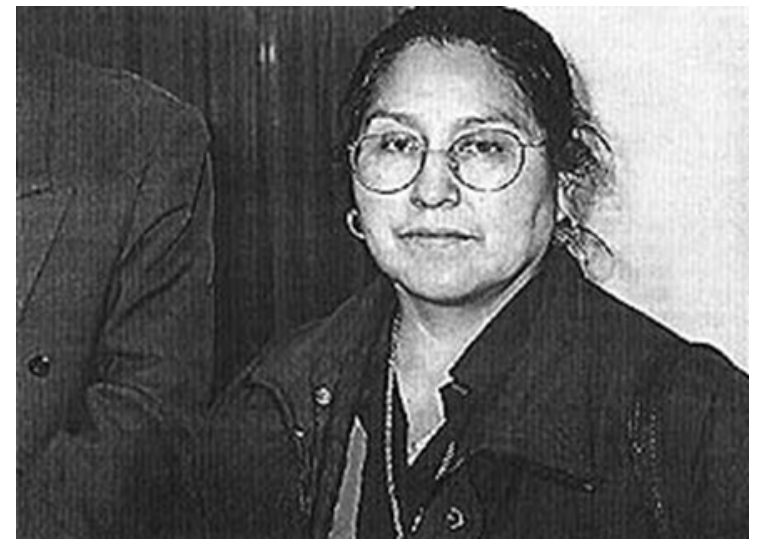

Fonte: (COLOMER, 1998)

A trajetória de Loyola Guzmán Lara se iniciou na cidade de La Paz, Bolívia, em 1943-44. Contudo, não é sobre sua infância que se tem construído uma memória, mas sim sobre sua militância precoce na Juventude Comunista Boliviana JCB -, com apenas 12 anos de idade, na guerrilha promovida pelo Exército de Libertação Nacional - ELN -, aos 24 anos, e, posteriormente, na sua atuação junto ao grupo de familiares de pessoas desaparecidas e detidas. Na Bolívia, durante os anos de regimes totalitários com curtos períodos de democracia (1964-1982), Lara foi presa, foi exilada, e seu esposo Melgar Antelo Félix foi preso e desaparecido na Bolívia (1971). Em 1983 retornou à Bolívia, após um período de exílio na Suécia (1980-1983), e integrou-se ao grupo de familiares denominado Associação de Familiares de Detidos, Desaparecidos e Mártires pela Liberação Nacional ASOFAMD -, tornando-se presidente desta por muitos anos, assim como da Federação Latino-Americana de Associações de Familiares de DetidosDesaparecidos - FEDEFAM.

Como se vê, nessas breves linhas, que de certa maneira apresentaram suscintamente as trajetórias dessas mulheres, elas passaram por contextos diferentes, eram de gerações distintas, possuíam posições políticas e sociais díspares. Carmen Castro era ligada a um Partido Tradicional e vinha de uma família abastada e importante no Paraguai. Isso deu legitimidade e muitas armas para sua luta em meio a um governo repressor e violento. Loyola Guzmán entrou para grupos de esquerda quando jovem, e continua na atualidade, com ideais e perspectivas de 
esquerda. Já Therezinha Zerbini, não participava de grupos nem de esquerda e nem de direita. Era de classe média alta, Católica, e, por uma série de acontecimentos em sua trajetória, tomou a frente na luta pela anistia e também pelos familiares.

Apesar dessas dessemelhanças em suas trajetórias, cada uma delas teve papel importante na luta contra a ditadura e na defesa pelos Direitos Humanos, foram elas que organizaram grupos de familiares de pessoas desaparecidas e detidas em seus países, e também lutaram pelo retorno à democracia.

\section{Movimentos de familiares}

Por meio de três excertos, podemos compreender como emergiram esses movimentos, assim como os motivos para se organizarem enquanto grupo: Loyola Guzmán ressalta a "necessidade" como o motivo para o surgimento da organização na Bolívia, esse movimento ocorreu no ano de 1978 em torno dos familiares dos guerrilheiros mortos em Teoponte - sob ordem do presidente General Alfredo Ovando Candia ${ }^{16}$-:

Sempre digo que é uma organização que ninguém gostaria de participar, pois é fruto de uma desgraça, e segundo que não havia partidos e sindicatos, todos estavam fechados, era difícil poder reclamar por seus companheiros, então o único que sobrava era por seus familiares e dentro dos familiares a maior parte dos presos eram homens (LARA, 2008, p.10).

Therezinha G. Zerbini comenta que o Movimento Feminino pela Anistia surgiu em 1975, com um pequeno grupo de 10 mulheres e que logo atingiu todo o Brasil:

Falando sobre o Movimento Feminino pela Anistia, a sra. Therezinha Zerbini
explicou que essa luta surgiu "numa hora em que o Brasil vivia dominado
pelo medo". Então, a mulher brasileira assumiu a responsabilidade de
deflagrar a luta pela Anistia, quando participava das promoções do ano
Internacional Mulher (patrocinado pela ONU) que visava integrar a mulher
no trabalho pela igualdade, desenvolvimento e paz (ZERBINI, 1979, p. 192).

Jorge Lara Castro em entrevista narra a trajetória de vida de sua mãe, Carmen Casco Miranda de Lara Castro, e conta como surgiu a Comisión de Defensa de los Derechos Humanos del Paraguay:

16 Sobre a Chacina de Teoponte: ASSOCIACIÓN DE FAMILARES DE DETENIDOS DESAPARECIDOS Y MÁRTIRES POR LA LIBERATACIÓN NACIONAL, 2008, p.19.

R. Inter. Interdisc. INTERthesis, Florianópolis, v.10, n.1, p. 190-211, Jan./Jul. 2013 
Minha mãe, Carmem Lara Castro, em 17 de junho de 1967, convocou intelectuais, militantes e jovens lá em casa, e como resultado dessa convocatória se fundou a primeira Comissão de Defesa dos Direitos Humanos do Paraguai. A data de 67 é muito importante porque estamos em plena ditadura e a ditadura nesse país tinha a característica de ser uma ditadura personificada [...] e o desenvolvimento da ditadura, a construção do regime ditatorial se realizou basicamente sobre a perseguição e a violação dos direitos humanos. Então, como havia muitos presos políticos indefesos, então essa mulher em condições bastante complicadas, em um país bastante isolado e praticamente desconhecido, e com um grupo de pessoas respeitáveis dessa sociedade, fundou essa comissão. Certo que nessa época não existiam ONGs e nem apoio, era a custa de convicção e esforço e um compromisso de luta permanente contra o próprio medo, tínhamos medo, então todos os dias tínhamos que fazer um exercício contra o próprio medo (CASTRO, 2008, p. 3).

Comparando estes três excertos, podemos ver claramente que os movimentos surgiram da necessidade, "da desgraça", e que eram tempos dominados "pelo medo", onde qualquer atividade era tida como suspeita, esses movimentos tiveram que agir com muita cautela e, como não havia outros meios para luta, pelo menos não meios legais, tiveram que criar sua própria organização, surgida da dor e da angústia.

Também encontramos nas falas destes entrevistados a perspectiva de que conforme a atuação nas organizações as mulheres tomavam consciência de sua luta como sendo política, como ressalta Loyola Guzmán Lara:

Algo em comum é que as organizações de familiares permitiram a muitas mulheres conhecer melhor a realidade de seu país e, de uma diferença inicial e inclusive uma oposição, teve uma incorporação nesta luta, na vida política. Talvez não militando diretamente em partidos, mas sim tomando uma atitude política (2008, p.12).

Jorge Lara Castro também salienta a importância da luta política das mulheres: "Essa foi à especificidade de todo Cone Sul, ou seja, o valioso foi que as mulheres tiveram um melhor compromisso político em situações bem complicadas" (CASTRO, 2008, p. 3).

Therezinha G. Zerbini em conferência aos deputados de São Paulo, organizado pelo Centro da Mulher Brasileira, em 1975, alertava para que as mulheres tomassem consciência de sua cidadania, apontando que a mulher deveria participar da luta, dizendo "ela tem direitos e deveres e nada cai do céu de graça para ninguém, nem direitos, nem liberdade, nem Anistia... O nosso dever é lutar". (ZERBINI, 1979, p. 54).

R. Inter. Interdisc. INTERthesis, Florianópolis, v.10, n.1, p. 190-211, Jan./Jul. 2013 
Devemos dizer aos homens "CHEGA! CHEGA dessa sociedade masculina, onde só vocês ficaram com o timão na mão. Também queremos participar. Vamos segurar juntos o timão e vamos dar os rumos que nós, homens e mulheres brasileiros, achamos que a embarcação deve tomar (1979, p. 56).

Como já foi dito anteriormente as mulheres usavam de estratégias para se protegerem da repressão, mas isso não impediu que sofressem ameaças, detenções e fossem vigiadas. Estas três personagens trazem em seus históricos antecedentes de detenções e ameaças. Loyola Guzmán foi presa duas vezes por seu engajamento político com o Exército da Libertação Nacional, em sua última detenção estava grávida e permaneceu presa por dois anos, vindo a ter seu segundo filho na prisão. Quando solta e já participando da organização de familiares em 1978 na Bolívia, teve de se exilar devido a grande repressão que se abateu sob os familiares durante o governo de Garcia Meza. Loyola teve seu companheiro detido e desparecido. Carmen C. M. Lara Castro, também foi detida por sua ligação com a Comissão de Direitos Humanos. Viviam sob ameaça "toda reunião, qualquer que fosse, uma reunião familiar era considerada altamente suspeita" (CASTRO, 2008, p. 6). Therezinha G. Zerbini, líder do Movimento Feminino pela Anistia, foi presa por duas vezes, a primeira vez foi devido à sua ligação com o $30^{\circ}$ Congresso da União Nacional dos Estudantes (UNE) em Ibiúna - Therezinha emprestou o sítio de um amigo de seu esposo, ex-general Zerbini, a Frei Tito (Frei dominicano que ajudava o movimento estudantil) para que ocorresse o congresso UNE. Sua segunda detenção ocorreu durante a Operação Bandeirantes ${ }^{17}$. Durante seis meses foi interrogada e ameaçada, mas essas detenções ocorreram anteriormente ao Movimento Feminino pela Anistia. Esse momento Ihe deu maior compreensão da crueldade contra os opositores ao regime (DUARTE, 2009, p.42-44).

Num estudo sobre as vozes femininas na resistência, Olivia Rangel Joffily (2005, p. 52-53) alerta para o uso do gênero como estratégia, assim como para a diferença de gênero na tortura. A autora defende, assim como outros autores, que em meio à guerra os papéis masculinos e femininos são modificados e as contradições de gênero se acentuam. Nesse sentido Loyola Guzmán Lara nos dá um exemplo claro, quando fala das estruturas que se modificaram e da reação das mulheres frente aos desaparecimentos:

${ }^{17}$ A OBAN ou Operação Bandeirante foi uma operação piloto, criada em 1969 no Estado de São Paulo, priorizava integrar os ministérios do exército, Marinha e Aeronáutica, Polícias Federal e Estadual com o intuito de reunir os aparatos de repressão para melhorar sua eficácia (SECRETARIA ESPECIAL DOS DIREITOS HUMANOS, 2007, p. 23). 
Acho que o tema do desaparecimento é para meter terror, paralisar a todos, mas não conseguiram esse objetivo porque reagimos; por isso eu digo "por que somos mais mulheres?", uma porque mais homens são reprimidos, os esposos, os filhos, porque na família normalmente, pelo menos até a década de 80 , os homens trabalhavam fora mais que as mulheres, depois que se deu uma incorporação massiva das mulheres ao trabalho, essa é uma razão porque se dedicavam todos e eu acredito fundamentalmente que este pensamento que as mães, as mulheres, eram mais consideradas na repressão, não era bem assim, mas se pensava assim (LOYOLA, 2008, p.12).

Therezinha G. Zerbini ressalta essa modificação nas relações de gênero, nas formas tradicionais das famílias, dando um depoimento no qual conta sobre a prisão de seu esposo, general Zerbini, após o golpe de 1964.

\begin{abstract}
Meus filhos sofreram muito, porque toda criança acredita e admira o pai, seja ele general ou pedreiro. Fomos todos muito machucados. Na altura em que estávamos, fomos alvo de imprensa sensacionalista. Os meios de comunicação podem fazer muito bem, mas também muito mal. Os repórteres têm muita força. Havia um programa na Tupi, do Mauricio Loureiro Gama, e um outro do Tico-Tico, que pisaram feio e caíram. Diziam que a revolução tinha sido feita para esmagar corruptos e os comunistas. Acontece que muitas das pessoas atingidas não eram nem uma coisa e nem outra. Então um dia tive que ouvir do meu filho: "O papai não é comunista, mas o que é ser corrupto?" Meu marido estava preso na época do dia 02 de maio - inteiramente incomunicável (ZERBINI, 1979, p. 138).
\end{abstract}

Os familiares atingidos sofreram de diferentes formas durante a ditadura, economicamente, pois muitas famílias dependiam financeiramente das contribuições de seus maridos e esposas, filhos, filhas; emocionalmente e psicologicamente, pois muitos familiares também foram presos, com o simples objetivo de colher possíveis depoimentos, além de que muitos foram usados como modalidade de tortura psicológica para com o detido. São inúmeras as formas e maneiras que encontraram para castigar, penalizar. O Brasil durante a ditadura foi um grande exportador de técnicas de tortura, exportando-as para os outros países do Cone Sul. ${ }^{18}$

As trajetórias de vida de Carmem Miranda Casco de Lara Castro, Therezinha G. Zerbini e Loyola Guzmán Lara se cruzam quando falamos na luta pelos Direitos Humanos num Estado de exceção. Três histórias individuais que se tornam coletivas por fazerem parte do social. Elas são únicas, mas colocam perspectivas específicas

\footnotetext{
${ }^{18}$ O Plano Condor foi um acordo maligno criado na década de 1970 entre os países do Cone Sul com o intuito de aprimorar a repressão, formando uma rede de informações que tinha por objetivo perseguir, torturar, matar e ocultar cadáveres, ou seja, caçavam seus adversários políticos. Sobre o Plano Condor: MARIANO, 2003.
}

R. Inter. Interdisc. INTERthesis, Florianópolis, v.10, n.1, p. 190-211, Jan./Jul. 2013 
sobre a luta das mulheres na Ditadura, sobre a resistência ao Estado e sobre suas próprias vidas ao olhar o passado e ver as modificações e as permanências, neste caso, as chagas de um passado de guerra, as lembranças do sofrimento e da luta, e os ganhos em participação política de tantas mulheres.

\section{Considerações finais}

Por meio do cruzamento dessas três perspectivas podemos encontrar novos apontamentos sobre esses movimentos, novos olhares a propósito desse passado recente que ainda merece maiores explicações. Esses movimentos foram muito importantes por lançarem nacional e internacionalmente o que estava ocorrendo nos países do Cone Sul nas décadas de 1964-1989, mostrando a face mais cruel das ditaduras: as violências contra os Direitos Humanos.

Ainda há muito que se pesquisar sobre esses movimentos, pois os documentos e trabalhos sobre eles são bastante escassos, principalmente sobre os movimentos provenientes da Bolívia, sendo raro encontrar algum artigo que aborde essa temática. Sobre a ditadura no Paraguai muito se escreve e alguns autores que tivemos acesso abordam a questão de movimentos sociais, destacam a intensa participação da Comissão de Defesa Direitos Humanos nas décadas de 1960 e 1970, com a liderança de Carmen C. M. Lara Castro. No Brasil, vários trabalhos abordam a questão dos movimentos pelos Direitos Humanos, trazendo à tona um problema recorrente sobre a abertura dos arquivos da Ditadura Militar, já se passaram décadas e ainda falar de Ditadura Militar no Brasil é um tabu, que graças a muitos pesquisadores é algo a ser lembrado e não esquecido. Além disso, o Brasil é o único país do Cone Sul que não apurou os crimes de direitos humanos cometidos durante a ditadura, mesmo tendo oficializado em lei $n^{\circ}$ 9.140/95 e reconhecido sua responsabilidade perante os brasileiros (SECRETARIA ESPECIAL DOS DIREITOS HUMANOS, 2007, p.19).

Essas personagens Loyola Guzmán Lara, Carmen C. M. de Lara Castro e Therezinha G. Zerbini organizaram esses movimentos para combater algo maior do que a proteção à família ou dar assistência aos presos, lutaram pela Paz, Liberdade e Dignidade em seus países atingidos por décadas de violências e injustiças. 


\title{
MOVED BY AFFECTION: THREE WOMEN IN RESISTANCE TO DICTATORSHIP IN BRAZIL, BOLIVIA AND PARAGUAY (1954-1989)
}

\begin{abstract}
This paper discusses the relationship of affection and commitment in political movements that fought for human rights during the civil-military dictatorships in Brazil, Bolivia and Paraguay, focusing on three women who occupied an important place in resistance to dictatorship. They are: Therezinha Godoy Zerbini, leader of the Feminine Movement for Amnesty, Brazil; Carmen Miranda Casco de Lara Castro founder of the Committee for the Defense of Human Rights in Paraguay; and Loyola Guzmán Lara, organizer of the Association of Detainees, Disappeared and Martyrs arrested and missing in Bolivia. The aim of this work is to propose a comparative analysis of the political action of these three women in three different countries, to understand how they acted at a period in which many people were paralyzed by dictatorships.
\end{abstract}

Keywords: Gender.Human Rights.Military Dictatorships.

\section{MOVIDAS POR EL AFECTO: TRES MUJERES EN RESISTENCIA A LA DICTADURA EN BRASIL, BOLIVIA Y PARAGUAY (1954-1989)}

Resumen: En este trabajo se analiza la relación entre afecto y compromiso político en los movimientos que lucharon por los derechos humanos durante las dictaduras cívico-militares en Brasil, Bolivia y Paraguay, centrando su mirada en tres mujeres que ocuparon lugares de reconocimiento en la resistencia a las dictaduras. Son ellas: Therezinha Godoy Zerbini, líder del Movimento de Mujeres por la Amnistía, en Brasil; Carmen Casco Miranda de Lara Castro, fundadora de la Comisión para la Defensa de los Derechos Humanos en Paraguay; y Loyola Guzmán Lara, organizadora de la Asociación de Familiares Detenidos, Desaparecidos y Mártires de los /las detenidos/as y de los/as desaparecidos/as en Bolivia. Por lo tanto, el objetivo de este trabajo es proponer un análisis comparativo de la acción política de estas tres mujeres, en tres países diferentes, para comprender sus formas de acciones en un momento en que muchas personas eran paralizadas por las dictaduras del Cono Sur.

Palabras-clave: Género. Derechos Humanos. Dictaduras Militares. 


\section{Referências}

A PREGAÇÃO DAS MULHERES. ANISTIA. [S.I]: Edição S.A. 1978.p. 13 (Acervo do Laboratório de Estudos de Gênero e História).

ALBERTI, Verena. Histórias dentro da história. In: PINSKI, Carla Bassanezi. Fontes Históricas. São Paulo: Contexto. 2008.

ASSOCIACIÓN DE FAMILARES DE DETENIDOS DESAPARECIDOS Y MÁRTIRES POR LA LIBERATACIÓN NACIONAL. Informe sobre las desapariciones Forzadas en Bolivia. 2a ed., La Paz: Garza Azul, 2008.

CAPDEVILA, Luc. Résistance civile et jeux de genre. France-Allemagne-Bolivie Argentine. Deuxième Guerre mondiale - annés 1970-1980. Annales de Bretagne et des Pays de l'Ouest. Tome 108, n. 2, 2001. Rennes: Presses Universitaires de Rennes, pp.103-128.

CASTRO, Jorge Lara. Entrevista concedida a Joana Maria Pedro e Cristina Scheibe Wolff. Assunção, Paraguai, 20/02/2008. Transcrita por Larissa Viegas de Mello Freitas, revisada por Andrei Martin San Pablo Kotchergenko. Acervo do LEGH/UFSC.

COLOMER, Victor. Loyola Guzmán: Bolívia y la Operación Cóndor. Cara a Cara. La Paz. 20 nov. 1998. Disponível em: http://cac.drac.com/199811/19981120.html. Acesso em: 13 abr. 2012.

COMISIÓN DE VERDAD Y JUSTICIA. Informe final - Anive haguã oiko - Sintesis y caracterización del regimén. Comisión de verdad y justicia. T. 1. Assucion, Paraguai: JC Medina. 2008.

CORVALÁN, Graziella. La accion colectiva de las mujeres urbanas en el Paraguay. In: RIVAROLA, Domingo, et al .Los movimentos sociales en el Paraguay. Assunsíon: Centro Paraguayo de Estúdios Sociologicos, 1986. p.91-136.

DIA DE LA MUJER PARAGUAYA. ABC Digital. Assunção. 28 fev. 2003. Disponível em: http://archivo.abc.com.py/2003-02-28/articulos/34308/dia-de-la-mujerparaguaya. Acesso em: 10 ago. 2012. 
DUARTE, Ana Rita Fonteles. Memórias em disputa e jogos de Gênero: O movimento Feminino pela Anistia no Ceará (1976-1979). Tese (Doutorado em História Cultural) - Universidade Federal de Santa Catarina, Centro de Filosofia e Ciências Humanas. Programa de Pós-Graduação em História. Florianópolis, 2009.

. Mulheres em guarda contra a repressão. In: PEDRO, Joana Maria; WOLFF, Cristina Scheibe; VEIGA, Ana Maria (Org.). Resistências, Gênero e Feminismos contra as Ditaduras no Cone Sul. Ilha de Florianópolis: Mulheres, 2011. p. 233-258.

HUNT, Lynn. A invenção dos direitos humanos. Uma história. Trad. Rosaura Eichenberg. São Paulo: Cia das Letras, 2009.

JELIN, Elizabeth. Los trabajos de la memoria. Madrid: Siglo XXI de España Editores, 2002.

Mulheres, Gênero e Direitos Humanos. In: Construindo a Democracia: Direitos Humanos, Cidadania e Sociedade na América Latina. São Paulo: EDUSP, 2006, p. 253-280.

JOFFILY, Mariana. Os Nunca más no Cone Sul: gênero e repressão política (19841991). In: PEDRO, Joana Maria; WOLFF, Cristina Scheibe; VEIGA, Ana Maria (Org.). Resistências, gênero e feminismos contra as ditaduras no Cone Sul. Florianópolis: Editora Mulheres, 2011, pp. 213-232.

JOFFILY, Olívia Rangel. Esperança Equilibrista - resistência feminina à ditadura militar no Brasil (1964-1985). Tese (Doutorado em Ciências Sociais) - Pontifícia Universidade Católica de São Paulo. São Paulo, 2005.

KOCKA, Jurgen. Comparison and beyond. History and Theory. Middletown: U.S.A. n. 42, p.39-44, Feb. 2003.

LARA, Loyola Guzmán. Entrevista concedida a Cristina Scheibe Wolff e Joana Maria Pedro (digital). La Paz, Bolívia, 14/08/2008. Transcrita por Gisele Maria da Silva e revisada por Luana Lopes. Acervo do LEGH/UFSC.

MARIANO, Nilson. As garras do Condor: como as ditaduras militares da Argentina, do Chile, do Uruguai, do Brasil, da Bolívia e do Paraguai se associaram para eliminar adversários políticos. Rio de Janeiro: Editora Vozes, 2003. 
PAZ, Alfredo Boccia. Represión política y género en la dictadura paraguaya. In: PEDRO, Joana Maria; WOLFF, Cristina Scheibe. Gênero, Feminismos e Ditaduras no Cone Sul. Ilha de Santa Catarina: Mulheres, 2010. p.74-93.

PEDRO, Joana Maria. Narrativas do Feminismo em países do Cone Sul (19601989). In: PEDRO, Joana Maria; WOLFF, Cristina Scheibe. Gênero, Feminismos e Ditaduras no Cone Sul. Ilha de Santa Catarina: Mulheres, 2010. p.115-137.

PEREIRA, Ligia Maria Leite. Algumas reflexões sobre histórias de vida, biografias e autobiografias. HISTÓRIA ORAL, 3. 2000. p. 117-127. Disponível em:

<http://revista.historiaoral.org.br/index.php?journal=rho\&page=article\&op=viewFile\&p ath[]=26\&path[]=20>. Acesso em: 10 de Julho de 2011.

PINTO, Celi Regina Jardim. Uma história do feminismo no Brasil. São Paulo: Fundação Perseu Abramo, 2003.

SADER, Emir; JIKINGS, Ivana. Enciclopédia Contemporânea da América Latina e do Caribe. Boitempo Editorial. São Paulo. 2006.

SCOTT, Joan. Gênero: uma categoria de análise útil à análise histórica. Educação e Realidade. Porto Alegre, v. 20, n.2, p.71-99. jul./dez., 1995.

SECRETARIA ESPECIAL DOS DIREITOS HUMANOS. Direito à memória e à verdade: Comissão especial sobre mortos e desaparecidos políticos. Secretaria Especial dos Direitos Humanos. Brasília: Comissão especial de Direitos Humanos, 2007.

THEML, Neyde; BUSTAMENTE, Regina Maria da Cunha. Historia Comparada: Olhares Plurais. História Comparada. Rio de Janeiro, v.1, n. 1., p.1-23. Jun/2007.

TRINDADE, Tatiana. O papel materno na resistência à ditadura: o caso das mães de Flávio Tavares, Flávio Koutzii e Flávia Schilling. Monografia - Universidade Federal do Rio Grande do Sul. Porto Alegre, 2009.

VIEZZER, Moema. Se me deixam falar - depoimento de uma mineira boliviana. 9a ed. São Paulo: Global, 1984.

WERNER, Michael; ZIMMERMANN, Bénédicte. Beyond comparison: histoire croisée and the challenge of reflexivity. History and Theory. Middletown: U.S.A. n. 45, p. 30-50, feb. 2006. 
WOLFF, Cristina Scheibe. O Gênero da esquerda em tempos de Ditadura. In: PEDRO, Joana Maria; WOLFF, Cristina Scheibe. Gênero, Feminismos e Ditaduras no Cone Sul. Ilha de Santa Catarina: Mulheres, 2010. p. 138-155.

WOLFF, Cristina Scheibe. Jogos de gênero na luta da esquerda armada no Brasil; 1968-1974. In: WOLFF, Cristina Scheibe; FÁVERI, Marlene de; RAMOS, Tânia Regina de Oliveira (Org.). Leituras em Rede: Gênero e Preconceitos. Florianópolis: Mulheres, 2007, p. 95-111.

ZERBINI, Therezinha Godoy. Anistia - Semente da Liberdade. São Paulo: Salesianas. 1979.

Dossiê:

Recebido em: Março/2013

Aceito em: Maio/2013 